Este artigo discute a função e a posição do pediatra diante das demandas articuladas pela modernidade. Propõe que o pediatra se engaje na prevenção $e$ na manutenção da saúde e defende a idéia de que o médico pediatra, apesar da formação recebida, deve tentar evitar fazer uma medicina simplista, que não incomode os pais e que seja rentável: aquela que vai do sintoma à receita.

Pediatria; prevenção; saúde.

SOME ASPECTS OF PEDIATRIC PREVENTION

This article discusses the function and the position of the pediatrician faced with the articulated demands of modernity. It proposes that the pediatrician becomes engaged in the prevention and maintenance of health, and defends the idea that the physician, the pediatrician, in spite of his/her training, should at least try to avoid practicing simplistic medicine, one which will not inconvenience the parents and be profitable: one which goes from the symptom to the prescription.

Pediatrician; prevention; health

\section{ALGUNS ASPECTOS DA PREVENÇÃO PEDIÁTRICA ${ }^{1}$}

\author{
Leonardo Posternak
}

Não é necessário que me lembrem que o valor de qualquer observação que eu faça depende de minha habilidade em conhecer a ação e os limites da doença física. Da certeza de que levei em consideração a doença ffsica depende meu direito em me deixar envolver pelo lado psicológico."

D. Winnicott

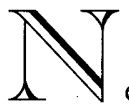

este fim de milênio observamos com surpresa a ocorrência de aspectos contraditórios na evolução social do ser humano. Por um lado muitas crianças desta sofrida América Latina estão imersas na pobreza, na doença e na falta de esperança. Por outro, acontecem progressos incríveis na esfera técnico-científica da medicina, especificamente ligados à pediatria (genética, imunologia, cirurgias pré-natais, diagnósticos laboratoriais e radiológicos sofisticados etc.). 
Nessa encruzilhada, nós, pediatras, devemos refletir e agir no sentido de defender e advogar pela criança, inserida nos vínculos familiares e sociais. Sabemos que, por sua essência, ela é débil e vulnerável e não pode, por si própria, agrupar-se e defender seus direitos. O Unicef declara: "A necessidade de importantes investimentos no cuidado dessa geração infantil, em meio dos graves problemas econômicos e sociais, aparece como um tema mobilizador que, por cima de países, ideologias e setores, possa unir de maneira solidária a nossa frustrada e impotente sociedade".

Essas crianças (devemos ter clara essa noção) serão uma parte substancial dos adultos, gestores das etapas do desenvolvimento brasileiro do próximo século, podendo talvez cumprir com caráter de urgência nosso sonho de um Brasil novo, inserido plenamente em um novo milênio. A pediatria deve ampliar e modificar suas metas e suas metodologias para desenvolver adequadamente essa enorme e fascinante tarefa; não haverá outros que o façam, se nós não o fizermos; aos pediatras, nos tocará essa responsabilidade no presente e no futuro imediato.

Assim, deveríamos estar fundamentalmente dedicados à atenção primária (primordial ou prioritária), que não devemos confundir com uma atenção precária da criança e da família em relação aos seus vínculos, centrada na identificação e no manejo adequado dos problemas de saúde física e psíquica, e não tão-somente das doenças e dos doentes. Devemos estar fundamentalmente engajados na prevenção dos danos e seqüelas, na promoção do bem-estar e na atitude educativa para com as famílias que nos consultam.

Resulta claro que o modelo médico que ainda se ensina nas nossas universidades e que continua vigente como ideologia na comunidade, incluindo os níveis de decisão, centra-se na idéia, falsa, na minha opinião, de que os recursos para a saúde são unicamente os hospitais modernos e aparelhados, os exames laboratoriais caros e sofisticados e o número de leitos para internação. (Reconheço que no Brasil isso tudo, em geral, está faltando, os hospitais sucateados, as verbas escassas, os doentes sem leito etc.)

Porém, devemos enxergar que esses recursos estão destinados, fundamentalmente, a combater a doença e secundariamente a preservar a saúde. $E$ isso não é uma simples discussão semântica; chamar de recursos de saúde aos destinados à erradicação da doença implica conceber que a primeira (saúde) só se obtém eliminando a segunda (enfermidade) e situa a ação curativa no centro do problema. Assim, a infra-estrutura, o planejamento e a própria tarefa médica, imprescindível para uma vida saudável, em todos os sentidos, ficam em um cone de sombras, e o médico e a medicação transformam-se no palco iluminado, funcionando como um ponto de 
apoio e equilíbrio. Esta é a noção de prevenção em nosso trabalho pediátrico cotidiano.

Nós, médicos, não conseguimos enxergar com eficiência e adequação a relação dos fatores psicológicos como facilitadores do aparecimento das doenças somáticas infantis. Alguns milênios antes que Freud descobrisse a psicanálise, Hipócrates já anunciara de maneira clara e contundente: "Não fica doente quem quer, senão quem pode". Duvido que na era pós-hipocrática e até nossos dias alguém tenha nos oferecido uma melhor definição do ser humano como uma verdadeira unidade psicossomática e tenha mostrado com tanta facilidade e firmeza a relação entre o psíquico e o orgânico. Essa compreensão do ser humano permite-nos, talvez (tomara que isso aconteça), um novo olhar sobre a criança, a família e a sociedade, que inclui os médicos como mantenedores da saúde ou, pelo contrário, como facilitadores de vínculos distorcidos e estressantes, que acabam sendo produtores de doença.

A dificuldade que temos para enfocar e integrar os aspectos psíquicos da criança em relação ao familiar e ao social, como coadjuvantes ou não do aparecimento do sintoma e da doença orgânica nos leva a fazer uma primeira pergunta: a relação entre as pessoas é o objeto da ciência médica?

A resposta lamentavelmente é negativa: a medicina organicista, centrada na doença, persiste com essa como com outras dúvidas básicas:

As questões subjetivas têm relação com o modo de se fazer vínculos? Os fenômenos psíquicos e os físicos têm ligação? O pensamento influencia nosso comportamento? Qual é o significado e a origem do sintoma?

Essas dúvidas ou lacunas persistem, porque são elementos que não podem ser submetidos a método de pesquisa científica cartesiana, não podem ser mensurados em percentuais, nem apresentados em estatísticas, sendo difícil achar a relação de causa e efeito entre eles, e, portanto, não conseguimos entender seu mecanismo fisiopatológico ou etiopatogênico, da maneira brilhante, clara e ate fácil como o fazemos com a febre reumática ou as pneumonias, por exemplo.

A segunda pergunta é: por que esse tipo de aproximação nos resulta difícil e ansiogênica?

Algumas hipóteses nos auxiliam na resposta, e a primeira delas aqui levantada tem a ver com a vocação, aquela força que nos empurra a ser pediatras. Poderia ser interessante reconhecer essas motivações inconscientes, se as aceitamos como fonte de energia que vai sofrendo muitas transformações, das quais a mais importante é a sublimação, que nos permite conciliar o prazer e o mandato 
social, no exercício de nosso trabalho. Algumas dessas forças que acabam determinando a pediatria como escolha são:

- Identificação com a criança.

- Reparação: nosso trabalho traz à tona a relação antiga com nossos pais, com toda a ambivalência e a agressividade que disso resultam. Ao cuidar de uma criança que sofre nos "transformamos" em bons pais ou mães, e isso também nos oferece a possibilidade de revide, em nome da criança frágil e desprovida que fomos e que ainda levamos junto a nós.

- Poder: dado pelo conhecimento, é a mais perigosa das forças, por nos oferecer a possibilidade de mandar, criticar e amedrontar os pais, através de uma relação assimétrica, alienada e alienante.

A segunda hipótese tem a ver com nossa formação. E interessante refletir sobre o começo do curso de medicina, que nos introduz logo no início ao estudo das ciências exatas, como a física, a química e a estatística. Isso nos marca de maneira indelével em nossa trajetória profissional e nas nossas atitudes como médicos. $\mathrm{O}$ ideal na nossa tarefa está representado pela exatidão, o rigor científico e a permanente busca de provas objetivas (testes quantitativos e de imagens), para determinar sempre a relação de causa e efeito. Outro ponto crítico acontece na anatomia, em que persiste a linha de raciocínio apoiado na observação de tudo o que seja perceptível e palpável e que, além do mais, põe-nos em contato com o cadáver na mesa de dissecção; sendo essa uma de nossas primeiras experiências como calouros, nos traz medo, repugnância e ansiedade, que por sua vez motivam as famosas brincadeiras, piadas inadequadas e a total falta de respeito, que acontecem muitas vezes só para nos acalmar.

Como conseqüência dessa primeira relação com o ser humano, morto e desfigurado, vão ficar impregnadas em nós a marca do distanciamento com a pessoa humana (doente ou sadia) e uma certa frieza. No ensino informal (na hora do café, nas noites de plantão), os médicos mais experientes, mais vividos, sugeriam-nos, muito convictos, que não deveríamos envolver-nos com a dor ou o sofrimento dos pacientes, pois, se assim o fizermos, nós também iremos sofrer, e que, se pudermos "manter distância" com as pessoas, seremos "mais objetivos" e, em conseqüência, "mais efetivos". Isso tem um efeito negativo em nossa postura como médicos; lamentavelmente esse tipo de ensino, por vir de pessoas com as quais o estudante identifica-se e venera, é muito marcante para os jovens, que logo formam a legião dos médicos distantes, interessados na doença, e não no doente, e que acabam falando do fígado cirrótico do leito 4 ou da interessante cardiopatia do leito 26 , sem 
enxergar a pessoa "dona" do fígado e do coração, e muito menos suas condições subjetivas.

A partir dessa deformação ideológica, quantas vezes ficamos frustrados e com raiva dos pacientes, porque, apesar de nosso empenho, de nossa competência e de nossa luta desmedida e inadequada pela objetividade, não conseguimos fechar de forma brilhante os diagnósticos, nem esclarecer a causa dos sintomas, e decidimos de maneira autoritária e dogmática que, se não temos diagnóstico, é simplesmente porque ele não existe, o paciente "não tem nada" ou é "piripaque" de um histérico, ou seja, se eu não sei por que uma pessoa tem dor, é porque ela seguramente não tem dor, está enganada ou tenta nos enganar. Não percebemos que a queixa em um órgão pode estar determinada em outro - no "órgão mental", no psiquismo -, e que o nosso diagnóstico, "disparado" como um rótulo, serve para ocultar o nosso despreparo e o nosso déficit no manejo de determinados sintomas psíquicos.

Assim, nossa onipotência continua aumentando, até que, uma vez formados, durante a passagem pela residência médica, atinge seu ponto máximo, ao sermos encaminhados a "salvar vidas", custe o que custar. Surge uma pergunta: onde é que fica a pessoa doente, onde pode acontecer o encontro entre as "pessoas" do médico e do paciente?

Para finalizar essa sucinta análise do período de formação, quero acrescentar que nas escolas médicas se nos ensina a perguntar, aconselhar, prescrever, enfim, somos ensinados a falar, porém, esquece-se de nos ensinar a ouvir, sendo esta uma questão fundamental, pois é por meio dessa posição que podemos entender as queixas das pessoas, e é assim que muitos diagnósticos começam a ser feitos.

Como o pediatra é essa figura tão importante na higiene mental da família, todos juntos, família e profissionais, deveríamos refletir sobre nossa tarefa, observando que o pediatra clássico ou tradicional, tal qual se forma nas faculdades, não tem tido mais que um minguado semestre em seu treinamento com o atendimento a crianças e que isso tem acontecido exclusivamente no meio hospitalar. $\mathrm{E}$ aí assistimos a casos graves, extremos ou atípicos, sem ter contato com o funcionamento de uma família em seu "habitat natural” e em condições normais, nem ocasião de estudar e pensar sobre a criança sadia, de maneira que a nossa eficácia e adequação, nesses aspectos, dependem absolutamente, sem exclusão, muito mais de nossa própria condição humanista e de nosso posicionamento cultural que de nossa formação universitária formal.

Nosso hábito, muito enraizado, de olhar para a criança como um ser singular e "orgânico", esquecendo ou negando que ele, na 
realidade, está imerso na família e, junto com ela, na sociedade, acaba contribuindo para a conservação de um ponto de vista visivelmente parcial e inadequado, que, tenho certeza, só vai mudar quando os pais, com sua sabedoria espontânea, começarem (como já está acontecendo) a exigir de nós, médicos de seus filhos, uma visão e uma postura dinâmica e integradora dos problemas infantis e familiares.

Sabemos, por exemplo, que para denunciar certas desarmonias familiares, provocadoras de estresse e ansiedade, a criança utiliza seu corpo, seja por meio de transtornos do comportamento, como no sono, apetite, atitudes agressivas, magrezas ou obesidades sem explicação clínica aparente, bloqueios pedagógicos etc., seja por meio das doenças do corpo, como nas somatizações, em que a criança apresenta certas dores (cabeça, abdome etc.) ou verdadeiras doenças (do crescimento, alérgicas etc.). Assim sendo, deveríamos ficar atentos a certas condutas dos pais que poderiam facilitar o aparecimento desses quadros psicossomáticos infantis, seja por questões subjetivas, ou por crises familiares imprevisíveis (econômica, luto, doença, perda etc.).

Um exemplo da clínica pediátrica pode nos auxiliar a entender a íntima relação entre o corpo e a mente. Faz algum tempo que os endocrinologistas infantis têm demonstrado que a baixa estatura na criança, além dos quadros nosológicos clássicos, poderia ser provocada por aspectos psíquicos; hoje se conhece a relação de causa e efeito desse fenômeno. O hormônio de crescimento (STH) apresenta seu pico secretório máximo pouco após o adormecimento, ou seja, na primeira fase do sono profundo, chamada dos movimentos oculares lentos (MOL). As crianças com transtornos de conduta por estresse, com ansiedade e hiperexcitação, facilitados à vezes por inadequação das condutas educacionais dos pais, com falta de limites etc., apresentam transtornos justamente nessa fase do sono. Assim, inibem a liberação do STH, levando secundariamente a uma alteração no crescimento, acarretando baixa estatura.

As famílias, em geral, chegam a nossos consultórios porque alguma coisa está acontecendo com seus filhos; freqüentemente é um sintoma corporal, mas junto com isso trazem também suas carências, medos, o desconhecimento e a necessidade de serem contidos por nós. Entretanto, os pediatras aparecemos ante seus olhos como alguém que tudo sabe e que, de uma maneira mágica, poderá resolver todos os seus problemas e se fará depositário de todas as suas preocupações e padecimentos.

Ledo engano; na realidade, pediatra e família estamos, desde o primeiro encontro, comprometidos em um vínculo alienado e alienante, sustentado em uma relação assimétrica, de impotência/onipotência, em que nós, pediatras, carregamos o estigma de curadores de sintomas. Tudo isso está condicionado pela falta de treino, experiên- 
cia e tempo para que possamos atender outras situações que não sejam, simplesmente, a eliminação do sintoma e tentar, então, refletir sobre nossos pacientes e suas famílias, de forma global e integradora.

É necessário que nós, pediatras, tenhamos um novo olhar sobre a criança, a família e a sociedade, com a nossa inclusão nesse meio como mantenedores da saúde ou, pelo contrário, como facilitadores de vínculos inadequados, que provocam o aparecimento da enfermidade. Fica claro, então, que atualmente o pediatra que se postula a si mesmo como médico, especialista em crianças, não está sendo justo consigo, nem com sua tarefa. Nenhum pediatra atende só a uma criança; pela sua função e localização, é o vetor natural para entrar no seio da família. Sua presença é requerida através dos códigos que os pais utilizam para nos comunicar o que eles acreditam ser uma doença do filho. Assim, é necessária uma primeira tomada de consciência: nenhum pediatra atende a uma criança, atende a uma família.

Os dados de pesquisa e da própria mídia têm possibilitado verificar que as relações familiares têm sido lugar e fonte de grandes conflitos, chegando mesmo a ser um lugar de violência. São esses mesmos meios de comunicação que transmitem ao mesmo tempo uma imagem idealizada dessas relações, como lugar de amor e felicidade. Deveríamos enxergar as relações familiares sem idéias preconceituosas, nem dogmáticas, como um lugar de afeto e de conflito, mas principalmente como um lugar que precisa ser cuidado. E preciso lembrar que o sintoma é um direito da criança pode corresponder a uma doença aguda ou crônica, porém, é sempre uma linguagem. Os pais podem apoderar-se dele, ou fabricá-lo, ou não entendê-lo; nós, pediatras, deveríamos tentar evitar fazer uma medicina simplista, que não incomode os pais e que seja rentável para nós: aquela que vai do sintoma à receita.

Por outro lado, sabemos que o estudo e o cuidado dos aspectos relativos à criança normal em desenvolvimento são um campo pouco valorizado e explorado, tanto pela pediatria como pela psicologia. Sem sintomas e sem doenças, uma criança geralmente não consegue despertar interesse por parte dos pediatras, que possuímos, basicamente, uma formação que privilegia o registro das enfermidades e seus sintomas, antes de dar valor aos cuidados com a saúde.

A medida que progredimos na compreensão de como se geram os processos de enfermidade, mais vivo e intrincado torna-se nosso campo de ação, podendo identificar os mecanismos psíquicos mediante os quais o pediatra pode influenciar a criança e a família, e vice-versa, como o grupo familiar pode, num plano inconsciente, influenciar a nossa atitude clínica, na consulta e até no receituário. Se assim não o fizermos, podemos acabar cristalizando 
um duplo curto-circuito: entre o corpo e a mente da criança, e entre a criança e sua família.

Caso não utilizemos os mecanismos integradores em nossa tarefa, poderemos ver dificultada ou inibida nossa atitude profissional, por famílias cujo funcionamento é enfermo e estressante e que, então, apresentam maiores possibilidades de enfermar seus filhos.

Reconhecemos, assim, dois importantes conceitos para que o nosso trabalho clínico seja adequado e eficaz: a criança sob risco psicológico e o pediatra sob risco terapêutico.

Para concluir, gostaria de focalizar o pediatra como um especialista, em primeiro lugar, em pessoas, que às vezes ficam doentes, mas que fundamentalmente têm problemas inerentes ao fato de estarem imersas em famílias e comunidades, e cuja solução requer um enfoque mais abrangente, que de fato não é o que surge habitualmente, quando só buscamos, de forma desesperada e teimosa, na atenção primária da criança, doenças que muitas vezes não existem e acabamos medicalizando, de maneira ineficaz e perigosa, a vida da criança e de sua família.

NOTA

1 Esta é uma versão modificada e corrigida a partir do artigo anteriormente publicado pela revista Pediatria Moderna, Vol. XXXIV, no 12, dezembro de 1998.

Recebido em 03/2000. 